\title{
Interregional differences of life expectancy in rural Russia - Assessment of socio-economic, demographic, behavioural and ecological factors
}

\author{
Tatiana Blinova, ${ }^{1}$ Svetlana Bylina, ${ }^{1}$ Victor Rusanovskiy ${ }^{2}$ \\ ${ }^{1}$ Institute of Agrarian Problems of the Russian Academy of Sciences (RAS); ${ }^{2}$ Yuri Gagarin State Technical \\ University of Saratov, Saratov, Russian Federation
}

\begin{abstract}
The article is aimed at studying the effects of social, economic, demographic, behavioural and environmental factors on the life expectancy of rural people in different types of regions. Using cluster analysis, we identified four relatively homogeneous groups of Russian regions in terms of life expectancy. The impact of socio-economic, demographic and environmental indicators on life expectancy of the rural population was assessed using regression models. We identified regions with low life expectancy for the rural population, and factors that have negative effect on life expectancy at birth. The main ones were alcohol abuse, high unemployment and emissions of pollutants into the air. The regression analysis showed that investments aimed at the development of health care, provision of social services and improvement of residential premises contributed to an increase in life expectancy. Significant factors in regions with high life expectancy were a
\end{abstract}

Correspondence: Tatiana Blinova, Institute of Agrarian Problems of the Russian Academy of Sciences (RAS), 94 Moskoskaya St, 410012, Saratov, Russian Federation.

Tel.: +79.276205557. E-mail: tatianvic@mail.ru

Key words: Clusters of regions; life expectancy; socio-economic; ecological and behavioural factors; regression modes; rural Russia.

Funding: the authors thank the Russian Foundation for Basic Research (RFBR) for financial support of the research project presented (project No 19-010-00229A).

Contributions: TB formulated a scientific problem, study design, interpreted the results, wrote a manuscript. SB performed an assessment of regression models. VR critically reviewed the manuscript and references search. All authors have read and approved the final version of the manuscript.

Conflict of interests: the authors declare no potential conflict of interests.

Received for publication: 5 March 2020

Revision received: 20 October 2020.

Accepted for publication: 21 October 2020.

(C) Copyright: the Author(s), 2021

Licensee PAGEPress, Italy

Geospatial Health 2021; 16:876

doi:10.4081/gh.2021.876

This article is distributed under the terms of the Creative Commons Attribution Noncommercial License (CC BY-NC 4.0) which permits any noncommercial use, distribution, and reproduction in any medium, provided the original author(s) and source are credited. lower number of recorded crimes per 100,000 of the population and a decrease in high unemployment, as well as an increase in educational expenses. In the group of regions where life expectancy of the rural population was approaching the average level in Russia, an important factor was also an increase in the level of education. We conclude that a regionally differentiated approach is necessary when introducing social policy changes, and measures aimed at increasing the life expectancy of the rural population should take into account the distinctive differences in socioeconomic development of the various regions of Russia.

\section{Introduction}

The social determinants of health constitute a conceptual framework for most research health inequalities, and identification of growth factors in life expectancy of populations. The theory of social determinants of health explains how society affects population health through norms, social institutions and mechanisms of social interaction. Studies of differences in life expectancy, as well as in health inequalities, between countries or regions are widely reported in the literature (Barlow \& Vissandjee, 1999; Costa-Font \& HernandezQuevedo, 2012; Bilas et al., 2014; Duque et al., 2019). Some studies examine the geographical features of the distribution of population by life expectancy (Shaw et al., 2005; Bayati et al., 2013). Others have addressed the causes of death in various socio-demographic groups (Canudas-Romo \& Becker, 2011; Chou \& Chen, 2019). The spatial variability of life expectancy largely depends on the economic, institutional, social, demographic, environmental development of countries and regions, as well as on the health behaviour.

A huge role is played by the social determinants of health associated with the level of education of the population, income, employment, unemployment, social status, health behaviour and availability of medical care (Marmot \& Wilkinson, 2006; Bayati et al., 2013; Bilas et al., 2014; Sasson, 2016; Duque et al., 2019). Lleras-Muney and Cutler (2010) have shown that highly educated people earn more than less educated people, and that these income differences can affect health. Educated people are also more inclined to control risks. The impact of unemployment on health and mortality constitute a no less important aspect of research as voiced by Wilkinson and Marmot (2003): 'Unemployment puts health at risk, and the risk is higher in regions where unemployment is widespread...unemployed people and their families suffer a substantially increased risk of premature death'.

Convincing results have been obtained that prove that social factors have a significant impact on the mortality rate of various age groups of populations. Thus, low socioeconomic status has proven to be a strong predictor of infant mortality from injuries (Chou \& Chen, 2019). Studies of marital status influence health behaviour and life expectancy of people of different ages are of great interest (Robards 
et al., 2012). Numerous studies have repeatedly proved that married people have a lower risk of morbidity and mortality than single people. Hilz and Wagner (2018) demonstrate that not only at a young age, but also at the age of 40 and older, marriage is closely linked to a positive health behaviour At the same time, these authors studied the relationship between partner status and health-related behaviour among the German population in the second half of life, namely at 40-85 years of age (Hilz and Wagner, 2018). A significant proportion of deaths in rural areas are associated with behavioural factors, in particular with excessive alcohol consumption, the role of which for poor health and reduced life expectancy has been shown by Shkolnikov et al. (2013). These authors emphasize that alcohol-related disorders affect not only health, but also the economic situation and social status of an alcohol-dependent person, as well as on his or her family. At the same time, the greater the volume of consumed alcohol, the higher the risks associated with its use (Higuchi et al., 2020), while other authors have noted that 'most efforts to change health behaviours have had limited success' (Kelly and Barker, 2016).

The availability and quality of medical services for a population, as well as the expenses allocated by the state for the development of health care, play an important role in reducing mortality and increasing life expectancy. In studies conducted both for industrialized and developing countries focus on the need to improve the quality and accessibility of health services (Nixon \& Ulmann, 2006; Footman et al., 2013). There are also studies evaluating the function of health production, which reflects the functional relationship between health status, which is measured by the indicator of life expectancy at birth, on the one hand, and health care inputs on the other, which include economic and social factors as well as environmental factors (Rayhan et al., 2019). Thus, interregional differences in life expectancy are explained by different conditions of socio-economic development, the level of education and employment of the population, the quality of housing and the environmental situation in the region in question. The set and combination of factors affecting the health and longevity of the population may be different depending on the characteristics of regions.

The purpose of our study was to identify the contribution of economic, social, demographic, behavioural and environmental factors to explaining interregional differences in life expectancy at birth of the rural population in Russia.

\section{Materials and methods}

\section{Study area}

The Russian Federation is located in eastern Europe and northern Asia. It ranks first in the world in terms of territory (17.1 million $\mathrm{km}^{2}$ ), a significant part of which lies in the permafrost zone, and ninth in terms of population (146,78 million people) (Rosstat, 2019a). There are 85 regions of the Russian Federation, which are united in eight federal districts - Central, North-Western, Southern, North Caucasian, Volga, Ural, Siberian, and Far Eastern. The average population density is 8.6 people per $\mathrm{km}^{2}$ with regional values ranging from 171.4 in the Moscow region to 0.1 in the Chukotka autonomous area (Rosstat, 2019b). Only $25.4 \%$ of the country's population, or 37.3 million people, live in rural areas, and the number of rural settlements is 17,380 (Rosstat, 2019a). The life expectancy of the rural population (71.67 years) is less than that of the urban one (73.34 years) (Rosstat, 2019b).

\section{Life expectancy}

There are great interregional differences in the life expectancy of the rural population as well as the socio-economic, demographic and environmental factors affecting life expectancy at birth in different types of regions. For example, according to 2018 data, life expectancy of the rural population in the Republic of Ingushetia was 81.27 years and in the Chukotka autonomous area only 50.91 years, a regional gap of more than 30 years (Rosstat, 2019b). However, such striking interregional contrasts are unnoticed when assessing the average Russian values of life expectancy at birth. In order to take into account the influence of interregional differences, we constructed a classification of the regions of the Russian Federation by the life expectancy of the rural population forming relatively homogeneous clusters. For each of the selected groups, descriptive statistics were calculated, correlation matrices constructed and regression models for the dependence of the life expectancy of the rural population estimated in terms of the socioeconomic, demographic and environmental features of development of the various regions of the Russian Federation.

\section{Methodology}

We applied cluster analysis, based on the k-means method, to study the rural population in different regions according to the life expectancy (https://www.real-statistics.com/multivariate-statistics/ cluster-analysis/). To identify the potential relationship between this measure and the social, economic, demographic, behavioural and environmental characteristics of the regional development affecting life expectancy at birth, stepwise regression analysis was used, where the variable with the weakest correlation was removed at each step. A sample including 82 of the 85 regions of Russia was used as three federal cities had no rural population. A database of variables for each of the 82 regions was created. We used the statistics of the Federal State Statistics Service (Rosstat, 2018a; Rosstat, 2018b; Rosstat, 2019a; Rosstat, 2019b). Multiple regression models are constructed using the statistical processing package STATISTICA 10 with the initial data pre-normalized (http://statsoft.ru/ products/new-features/STATISTICA10.php).

\section{Independent variables}

Educational structure of the population; proportion of the population with incomes below the subsistence level; number of doctors per 10,000 people; number of nursing staff per 10,000 people; investments in fixed assets aimed at developing health care and the provision of social services; total area of residential premises per inhabitant; proportion of the total area of residential premises equipped with water supply, sewage, gas supply and heating; density of public roads with hard surface; consolidated budget expenditures on education, healthcare and social policy were used as social variables. In addition, the share of the rural working age population was used as part of independent demographic variables.

\section{Economic variables}

Share of gross added value (formerly GDP at factor cost $=$ total value added) of agriculture, forestry, hunting and fishing in the economy of the region; unemployment rate calculated according to the methodology of the International Labour Organization (ILO). 


\section{Environmental variables}

Emissions of pollutants into the atmosphere; discharge of contaminated wastewater into landbound water bodies.

\section{Behavioural variables}

Number of patients with alcoholism registered in medical institutions; number of recorded crimes per 100,000 people. All these were used as independent variables with life expectance at birth used as the dependent variable.

\section{Statistics}

Modeling of the relationship between life expectancy of the rural population and socio-economic, demographic, environmental, behavioural factors has been performed both for Russia as a whole and for clusters of regions. We used stepwise regressions in order to determine the most significant factors and determinants that affect the life expectancy of the rural population in the regions of Russia. The dependent variable in the multiple regression models was life expectancy at birth; previously selected variables were used as independents. An econometric assessment of the influence of selected factors on the value of the life expectancy of the rural population at birth was performed using the model:

$Y_{i}=\beta_{0}+\beta_{1} X_{i}+\beta_{2} Z_{i}+\beta_{3} E_{i}+\beta_{4} B_{i}+\beta_{5} D_{i}+\varepsilon_{i}$

where: $Y$ - life expectancy at birth, $X$ - economic, $Z$ - social, $E$ - environmental, $B$ - behavioural, $D$ - demographic factors, $i$ - region, $\beta$ regression coefficient that measures relative contribution of the independent variable, $\beta_{0}$ - constant, $\varepsilon$ - random error. Regression models were evaluated using the ordinary least squares method. Five different model specifications were used for the assessment. An econometric assessment carried out for Russia as a whole and for the four identified clusters separately shows that there are differences in life expectancy models for regions of different types.

\section{Results}

\section{Classification of regions of the Russian Federation}

The results of the cluster analysis is the classification of Russian regions by the life expectancy of the rural population, and a description of socio-economic profile of the selected groups. Cluster analysis of 82 regions, included in the sample, was completed by the k-means method with the aim of dividing regions into relatively homogeneous groups. Based on the classification results, a map, reflecting the characteristics of interregional differences in the life expectancy of the rural population, was constructed (Figure 1). The first group represents the territories with the highest life expectancy of the rural population (70.96-80.1 years). The second group includes regions with indicators of the life expectancy of the rural population close to the average for Russia (68.97-70.79). In the regions of the third group, the life expectancy of the rural population is moderately low (67.05-68.83), and in the regions of the fourth group it is the lowest (55.3-66.83). For all groups, the average values of all the studied indicators were measured and descriptive statistics were described. A description of the socio-economic profile of the selected clusters is presented in Table 1 .

The first group includes 17 regions with high life expectancy at birth, which is higher than the average Russian value. The first group is dominated by the regions of the North Caucasus and Southern Federal Districts, with favourable climatic conditions for the development of not only diversified agriculture, but large recreational areas. The first group also included the most developed territories of the Central, North-West and Volga Federal districts. The population over 15 years with higher education per 1000 people is higher than the average for the Russian Federation and other groups. Housing quality indicators, in particular, the proportion of the total area of residential premises equipped with water supply, gas supply and heating, in most regions are higher than the average in the Russian Federation and other groups. In the regions

Table 1. Socioeconomic profile of groups of regions.

\begin{tabular}{|c|c|c|c|c|c|}
\hline Variables & In full & Group 1 & Group 2 & Group 3 & Group 4 \\
\hline Life expectancy at birth (years) & 70.5 & 73.7 & 70.6 & 68.6 & 65 \\
\hline $\begin{array}{l}\text { Share of gross added value of agriculture, forestry, hunt-ing and fishing } \\
\text { in the region's economy (\%) }\end{array}$ & 5.4 & 14.5 & 9.6 & 8.8 & 6.9 \\
\hline $\begin{array}{l}\text { Investments in fixed assets aimed at health care devel-opment and the provision } \\
\text { of social services (mln rou-bles) }\end{array}$ & - & 2944.3 & 1765.3 & 1217.5 & 1454.1 \\
\hline Consolidated budget expenditures on health and social policy (mln roubles) & - & 34964 & 29671 & 25645 & 22726 \\
\hline Unemployment rate (\%) & 8 & 10.6 & 6.7 & 7.6 & 10.7 \\
\hline The number of patients with alcoholism registered in medical institutions (per 100,000) & 984.0 & 744.9 & 1288 & 1129.4 & 1504.7 \\
\hline The number of recorded crimes (per 100,000) & 1473 & 1027.2 & 1284.5 & 1690.1 & 2101.1 \\
\hline The number of doctors (per 10,000) & 46.4 & 42.8 & 45.5 & 44.5 & 50.6 \\
\hline The number of divorces (per 1000 marriages) & 4.1 & 3.4 & 4.2 & 4.3 & 4.7 \\
\hline Population over 15 years with higher education (per 1000) & 111 & 137 & 110 & 102 & 92.7 \\
\hline Population over 15 years with full secondary education (per 1000) & 233 & 268 & 217 & 210 & 214 \\
\hline The proportion of the total area of residential premises equipped with water supply (\%) & 81.9 & 83.5 & 79.8 & 74.3 & 72 \\
\hline The proportion of the total area of residential premises equipped with gas supply (\%) & 66.3 & 82.7 & 82.5 & 63 & 39.4 \\
\hline Density of paved public roads (km per $1000 \mathrm{~km}^{2}$ of territory) & 62 & 440 & 272.6 & 170.3 & 50.2 \\
\hline Emissions of pollutants into the atmospheric air (thousand tons) & & 104.5 & 196.7 & 254.2 & 269.6 \\
\hline $\mathrm{N}$ (number of regions) & 82 & 17 & 24 & 22 & 19 \\
\hline
\end{tabular}

Source: own calculation based on Rosstat data. 
of this group, the number of patients with alcoholism registered in medical institutions per 100,000 people, the number of registered crimes, and the number of divorces per 1000 marriages is lower than the average for Russia and other groups. In terms of unemployment, measured by the methodology of the ILO, there are significant intra-group differences. Along with the highest possible unemployment rate, typical for the republics of the North Caucasus and the Southern Federal District, low unemployment takes place in the Moscow and Leningrad oblasts.

The second, most numerous, group includes 24 constituent entities of the Russian Federation with indicators of life expectancy of the rural population close to the average for Russia, and in 11 regions they are higher than the national average. The regions of this group have the lowest unemployment rate, and the share of the total area of residential premises equipped with gas supply is higher than the average in the Russian Federation and regions of the third and fourth groups. In the third group, consisting of 22 subjects of the Russian Federation, the life expectancy of the rural population is lower than the average in the Russian Federation by one, two or three years.

The fourth group consists of 19 regions where the life expectancy of the rural population is more than 3 years less than the average in the Russian Federation. The composition of the fourth group is dominated by the regions of the Siberian and Far Eastern Federal districts, where areas are sparsely populated. In this group, the share of agriculture and forestry, hunting and fishing in the economy of the regions is the lowest, with the exception of the Kamchatka Territory, Pskov Oblast and the Jewish autonomous oblast. This group is characterized by the high relative number of patients with alcoholism registered in medical institutions (with the exception of the Krasnoyarsk Territory); the level of alcohol abuse in the population exceeds both the average Russian value and the indicators of other groups. The number of recorded crimes per 100,000 people is also high. The number of divorces per 1000 marriages exceeds the average Russian indicator in all regions except the Republic of Tuva.
Further research was aimed at regression analysis and quantification of the factors affecting the life expectancy of the rural population in the regions of the four selected groups.

It is necessary to identify which factors are statistically significant in different clusters, to determine the differences in the composition of factors and the degree of their influence on the life expectancy of the rural population. Evaluation of regression models will identify social, economic, environmental and behavioural factors that directly affect the growth of life expectancy in different types of regions.

\section{Results of regression analysis}

The results of the regression analysis showed that there are differences in the models of life expectancy of different types of regions (Table 2). The model, calculated for Russia as a whole, demonstrates the dependence of the life expectancy of the rural population on the factors of the social environment safety: coeffi-

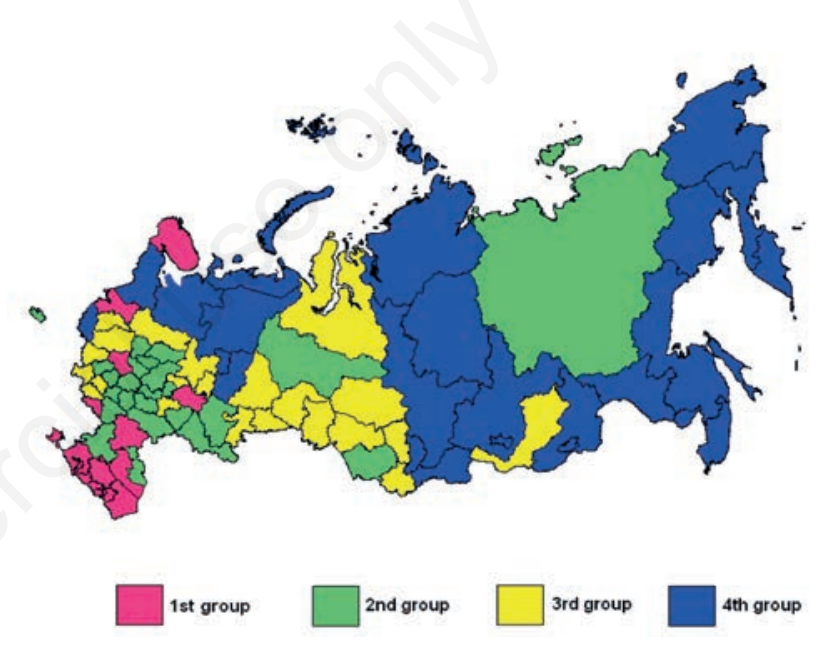

Figure 1. Classification of regions of the Russian Federation.

Table 2. Regression models.

\begin{tabular}{|c|c|c|c|c|c|}
\hline Variables & Model RF & Model 1 & Model 2 & Model 3 & Model 4 \\
\hline Constant & 5.930 & 4.449 & 2.292 & 6.135 & 6.239 \\
\hline Consolidated budget expenditures on education & & 0.306 & & & \\
\hline Consolidated budget expenditures on social policy (mln roubles) & & & 0.274 & & \\
\hline $\begin{array}{l}\text { Investments in fixed assets aimed at the development of health care and the } \\
\text { provision of social services (mln roubles) }\end{array}$ & & & & & 0.628 \\
\hline Unemployment rate (\%) & & -0.248 & -0.480 & & -0.497 \\
\hline The number of patients with alcoholism, registered in medical institutions (per 100,000) & -0.430 & & & & -0.817 \\
\hline The number of recorded crimes (per 100,000) & -0.237 & -0.495 & & -0.327 & \\
\hline The number of nurses (per 10,000) & 0.137 & & & & \\
\hline Proportion of rural population of working age (\%) & & 0.392 & & & \\
\hline Population over 15 years with higher education (per 1000) & 0.143 & & 0.320 & & \\
\hline Population over 15 years with full secondary education (per 1000) & -0.202 & & & -0.337 & \\
\hline The proportion of the total area of residential premises equipped with gas supply (\%) & 0.287 & & 0.387 & & 0.335 \\
\hline Emissions of pollutants into the atmospheric air (thousand tons) & & & & & -0.311 \\
\hline$R^{2}$ & 0.872 & 0.951 & 0.836 & 0.848 & 0.932 \\
\hline F-test & 82.972 & 53.096 & 31.023 & 53.188 & 33.075 \\
\hline Significance of F-test & 0.000 & 0.000 & 0.000 & 0.000 & 0.000 \\
\hline
\end{tabular}


cients of indicators that determine the level of crime and the number of patients with alcoholism registered in medical institutions have high values. The negative impact of excessive alcohol consumption on life expectancy is most pronounced in the regions of the fourth group, and the negative impact of crime is most pronounced in the regions of the first group. The high unemployment rate calculated according to the ILO methodology is a significant prediction that negatively affects life expectancy in the regions of the first, second and fourth groups, respectively.

A significant positive factor is the gasification of housing, which is important for the villagers both for cooking and for heating residential premises. In our studies, an analysis of the correlation between indicators of the quality of housing conditions and the life expectancy of the rural population indicates a significant positive effect of the availability of heating, gas and water in homes (Blinova et al., 2020). A gas supply indicator approximating the quality of housing was selected as the factor of the model. The effect of this indicator on the life expectancy of the population of the regions of the second and fourth groups is most pronounced. An important role is played by the level of education of the population. According to the obtained model, the rural population with higher education is more likely to live longer than people with a low educational level. The sixth indicator that has a positive effect on increasing the life expectancy of the rural population, is the number of nursing staff per 10,000 people, which reflects the degree of access to medical care.

Despite the fact that marital status plays an important role, our analysis did not reveal a significant relationship between the number of divorces per 1000 marriages and the life expectancy of the rural population. Perhaps this is due to the fact that other factors play a more important role. Analyzing the impact of environmental and demographic factors, in addition to socio-economic ones, has made the research more comprehensive. All obtained models and their coefficients are significant at the 5\% level. The performed estimation of the regression equations describes from $83.6 \%$ to $93.2 \%$ of the variation of the independent variables.

\section{Discussion}

The article examines the contribution of economic, social, demographic, behavioural and environmental factors explaining interregional differences in life expectancy at birth of the rural population in Russia. The results of the study revealed a high dependence of life expectancy at birth on the conditions, quality and lifestyle of people, as well as on the level of economic development, features of social organization and environmental conditions in the region. It was found out that availability of medical services for the rural population, housing quality, a high level of education are positively associated with the life expectancy of the rural population of Russia, while alcohol abuse, unemployment, low educational level of the population and high crime in the region have negative effect. Our research has confirmed the important role of the behavioural factors in the system of social determinants of health, which coincides with the conclusions of other authors. The number of patients with alcoholism per 100,000 people ( $\beta$-coefficient -0.430$)$ has the most significant negative effect; the crime rate in the region ( $\beta$-coefficient -0.237 ) is the second negative significant factor, which is consistent with the results of studies by other authors. Scientists call alcohol mortality one of the explanatory reasons for the gap in life expectancy at birth in Russia and European countries (Shkolnikov et al., 2013). Rural territories in Russia are characterized by high mortality of the working-age population from external causes of death, a significant part of which is explained by alcohol abuse. Not only in Russia, but also in other countries, suicide mortality is associated more with alcohol abuse (Yeom, 2019).

The significant factor that positively affects life expectancy is the level of education. Cutler and Lleras-Muney (2010) explored possible explanations for the relationship between education and health behaviour, they showed that income, health insurance, and marital status can account for about 30 percent of the educational gradient, knowledge and cognitive ability explaining another 30 percent. A significant proportion of deaths in rural areas are associated with behavioural factors, which, in turn, depend on the level of education. In this study a high level of education has a positive effect on the life expectancy of the rural population. The impact of unemployment on life expectancy was noted in three groups of regions (first, second and fourth). Jobs creation and diversification of employment structure are important areas of rural development. At the same time having a job will not always protect physical and mental health: job quality is also important (Wilkinson and Marmot, 2003). The simulation results for the regions of the first group, where the life expectancy of the rural population is higher than the average of the Russian Federation, showed the positive impact of higher government spending on education and an increase in the share of the working-age population. The positive significance of the growth of investments aimed at the development of health care and the provision of social services was revealed in the fourth group.

The authors' study also revealed a positive effect of the housing quality on the life expectancy of the rural population. It should be noted that the impact of indicators reflecting environmental living conditions on the life expectancy of the population will exert in the medium and long term. In addition to the considered factors, our study confirms the impact of the availability of health services for the rural population. In Russia, improving the availability and quality of health care is a priority area of the state social policy. The increase in the life expectancy of the population to 80 years by 2030 has been determined as a part of the national goals and strategic objectives of the development of Russia (Ministry of Health Care of the Russian Federation, 2018). The steady growth of real income of citizens, poverty reduction, improvement of housing conditions, and accelerated implementation of digital technologies in the economy and social sphere are envisaged.

There are some limitations in this study. Firstly, for individual variables, the lag structure of the regression equation could be more suitable, since it takes some time for social, economic and environmental conditions to affect the health, mortality and life expectancy of the population. However, for other variables that reflect, for example, the number of crimes, lag dependence is less preferable. Secondly, the study did not cover all socio-economic, demographic and environmental factors, but only a part of them that were approximated by twelve variables. At the same time, key factors that have a decisive influence on the life expectancy of the rural population were included in the regression equation, as evidenced by the high values of the coefficient of determination in the models.

Thus, the study found out high interregional differences in the life expectancy of the rural population. The obtained results confirm our hypothesis about the significant role of not only environmental factors, but also behavioural factors, which depend on the 
person himself, his lifestyle and decisions concerning health care. Our study showed that the interregional variability of life expectancy of the rural population is explained by a whole range of factors, which include both the features of the socio-economic and environmental development of the Russian regions, as well as the lifestyle and health behaviour.

In our opinion, it is necessary to form a new paradigm of rural development, which is based on improving the security of the social environment, strengthening human health, increasing the duration of his active life, diversifying the structure of jobs and income sources of villagers, expanding the opportunities for rural development. However, the participation of rural population in improving their health and increasing life expectancy is necessary.

The regionally differentiated approach is necessary; measures aimed at increasing the life expectancy of the rural population should take into account the peculiarities of the socio-economic development of regions. In addition, the geographical distribution of health risks is important, and rural areas with the lowest possible life span should be in the focus of special attention when implementing social policy. In order to take into account the influence of interregional differences, a classification of the regions of the Russian Federation by the life expectancy of the rural population has been developed and four relatively homogeneous clusters have been formed. Regression models were constructed not only for the rural population of Russia as a whole, but for each of the four selected groups of regions. An important task of the study was to find out which socio-economic, demographic and environmental factors determine the risks of low life expectancy in a great measure. We determined regions with a low life expectancy of the rural population, and identified factors among which the high number of patients with alcoholism, the unemployment rate calculated according to the ILO methodology, and emissions of pollutants into the air are the most significant. They have a negative relation with the life expectancy in the regions with a low life expectancy of the rural population. At the same time, investments aimed at the development of health care and the provision of social services, the improvement of residential premises (the proportion of the total area of residential premises equipped with gas supply), contribute to an increase in life expectancy. The results of the regression analysis showed that the regions of the fourth group with the lowest life expectancy at birth should be the subject of special attention.

Further research will be aimed at the development of spatial models, it is planned to conduct a spatial analysis of the determinants of the life expectancy of the rural population in 2010-2020, which will reveal patterns and key trends in the life expectancy of the rural population and the determining factors, the composition of which we plan to expand.

\section{Conclusions}

The study of inequality in life expectancy associated with the geography of the population is relevant and practically significant; because it allows the identification of a group of factors explaining some interregional differences. They include not only the features of the socio-economic and environmental development of the Russian regions, but also health behavioural variables, whose role needs to be strengthened.

The results confirm a high correlation between the life expectancy at birth of the rural population on the one hand, and the level, quality and living conditions of people, unemployment rate, and environmental situation in the region on the other. It explains the contribution of economic, social, demographic, behavioural and environmental factors to the interregional differences in life expectancy at birth of the rural population in the rural Russia.

\section{References}

Barlow R, Vissandjee B, 1999. Determinants of national life expectancy. Can J Dev Stud 20:9-28.

Bayati M, Akbarian R, Kavosi Z, 2013. Determinants of life expectancy in Eastern Mediterranean Region: a health production function. Int J Health Policy Manage 1:57-61.

Bilas V, Franc S, Bošnjak M, 2014. Determinant factors of life expectancy. Coll Antropol 38:1-9.

Blinova T, Bylina S, Rusanovskiy V, 2020. Factors affecting the life expectancy at birth of the rural population in Russia. Ponte 76-(1):9-18.

Canudas-Romo V, Becker S, 2011.The crossover between life expectancies at birth and at age one: the imbalance in the life table. Demogr Res 24:113-44.

Chou AK, Chen D-R, 2019. Socioeconomic status and deaths due to unintentional injury among children: A socio-spatial analysis in Taiwan. Geospat Health 14:25-34.

Costa-Font J, Hernandez-Quevedo C, 2012. Measuring inequalities in health: what do we know? What do we need to know? Health Policy 106:195-206.

Cutler D, Lleras-Muney A, 2010. Understanding differences in health behaviours by education. J Health Econ 29:1-28.

Duque AM, Peixoto MV, Lima SVMA, Goes MAO, Santos AD Araújo KCGM, Nunes MAP, 2019. Analysis of the relationship between life expectancy and social determinants in a north-eastern region of Brazil, 2010-2017. Geospat Health 13:345-52.

Footman K, Roberts B, Mills A, Richardson E, McKee M, 2013. Public satisfaction as a measure of health system performance: a study of nine countries in the former Soviet Union. Health Policy 112:62-9.

Higuchi S, Moriguchi Y, Tan KHX, 2020. Psychometric validation of the Japanese version of alcohol quality of life scale (AQoLS-Japan) in the treatment of patients with alcohol use disorder. Qual Life Res 1:223-35.

Hilz R, Wagner M, 2018. Marital status, partnership and health behaviour: findings from the German Ageing Survey (DEAS). Comp Popul Stud 43:65-98.

Kelly M, Barker M, 2016. Why is changing health-related behaviour so difficult? Public Health 136:109-16.

Marmot M, Wilkinson, RG (Eds.), 2006. Social determinants of health. Oxford University Press, Oxford, UK, pp 376.

Ministry of Health Care of the Russian Federation, 2018. National project "Health care". Available from: http://government. $\mathrm{ru} / \mathrm{info} / 35561 /$

Nixon J, Ulmann P, 2006. The relationship between health care expenditure and health outcomes. Eur J Health Econ 7:7-18.

Rayhan I, Hasan R, Akter M, 2019. Estimating Health Production Function for the South Asian Countries. Int J Econometr Financial Manage 7:12-9.

Rosstat, 2018a. Regions of Russia. Socio-economic indicators. 2018: statistical book. Rosstat, Moscow, Russia.

Rosstat, 2019b. Russian statistical yearbook. 2018: statistical book. Rosstat, Moscow, Russia. 
Rosstat, 2019a. Russia in Figures. 2019: statistical handbook. Rosstat, Moscow, Russia.

Rosstat, 2019b. Demographic yearbook of Russia. 2019: statistical book. Rosstat, Moscow, Russia.

Robards J, Falkingham J, Evandrou M, Vlachantoni A, 2012. Marital status, health and mortality. Maturit 73:295-9.

Sasson I, 2016. Trends in life expectancy and lifespan variation by educational attainment: United States, 1990-2010. Demography 53:269-93.

Shkolnikov V, Andreev E, McKee M, Leon D, 2013. Components and possible determinants of decrease in Russian mortality in
2004-2010. Demogr Res 28:917-50.

Shaw JW, Horrace WC, Vogel RJ, 2005. The determinants of life expectancy: an analysis of the OECD Health Data. South Econ J 71:768-83.

Wilkinson R, Marmot M, 2003. Social determinants of health: the solid facts. 2nd ed. World Health Organization, Geneva, Switzerland, Publ. no. 31

Yeom Y, 2019. Population-level alcohol consumption and suicide mortality rate in South Korea: An application of multivariable spatial regression model. Geospat Health 14:163-70. 